\title{
What do Nursing Students have to say about Occupational Health and Safety as University Undergraduates?
}

\author{
By Rose Boucaut* \\ Lynette Cusack
}

\begin{abstract}
Nursing is a high risk profession in terms of occupational health and safety (OHS) as is evident in the extent of illness and injury sustained by nursing practitioners worldwide. The purpose of this pilot study was to more fully understand nursing students' perspectives about clinical and non-clinical OHS. The study was undertaken at an Australian university in 2014. It was descriptive exploratory in nature. A comprehensive literature search was undertaken. Two focus groups were conducted, using semi-structured interview questions, one with first year students and one with third year students. There were some similar themes between the literature reviewed and focus group findings. The principal theme for non-clinical OHS issues was "Pedestrian Concerns". Spanning life both on and off campus, this theme encompassed issues of self-care including stressors related to work-life balance and the transition from school (or pre-university) to university student. Students were able to identify hazards when sharing their concerns and provide suggestions for their management. This information can be used by staff to enhance all students' university experience.
\end{abstract}

Keywords: Nursing students, Occupational health and safety, Risk management.

\section{Introduction}

From an occupational health and safety (OHS) perspective, globally nursing is a high risk profession. This is evident in the extent of illness and injury sustained by nursing practitioners world-wide (National Institute for Occupational Safety and Health 2014). Common occupational hazards faced by nurses during their work have been widely reported (Stokowski 2014, National Institute of Occupational Safety and Health 2014, Australian Safety and Compensation Council 2008). Similarly one would expect that student nurses face OHS issues during their training. Staff can learn from students about concerns they have for their health and safety, and doing so is an integral part of consultation about OHS. Further, staff have a duty of care to their students.

This paper describes the non-clinical OHS issues expressed by Australian nursing students from a broader study that aimed to more fully understand nursing students' perspectives about clinical and non-clinical OHS issues. The intent was to subsequently consider this information when planning future OHS teaching and management initiatives for undergraduate nursing students.

\footnotetext{
${ }^{*}$ Health and Safety Officer, School of Nursing, University of Adelaide, Australia.

${ }^{\dagger}$ Senior Lecturer, School of Nursing, University of Adelaide, Australia.
} 


\section{Method}

In order to gain an understanding about OHS issues experienced by nursing students the authors undertook a pilot study to explore this topic in an Australian university. As a first step the authors set out to determine the extent and nature of student OHS issues reported in the literature.

\section{Literature Review}

A comprehensive search of peer reviewed literature using PubMed was undertaken to answer the question: What are the non-clinical OHS issues experienced by nursing students in undergraduate University programs. A snowball approach was used to identify further references from previously sourced articles. The PubMed database was searched for primary research studies written in the English language published over the five year period between $1^{\text {st }}$ September 2009 - 2014. The rationale for a five year period was related to reviewing the most current literature on OHS issues for students. The search terms used were occupational health and nursing students (Table 1). The search revealed 410 papers which were considered for closer scrutiny according to their title and abstract. The majority of papers related to clinical issues, however a small number reported on non-clinical issues and some reported on both. Articles were selected for their content about OHS associated with non-clinical issues, as that is the focus of the current paper. Six articles that described primary research were retained, others were excluded. Additional information was also sought from wider reading about the subject.

Table 1. Logic Grid of Terms Used for the Comprehensive Literature Search

\begin{tabular}{|c|c|}
\hline Occupational Health & Nursing \\
\hline $\begin{array}{l}\text { Occupational health[mh] OR } \\
\text { occupational health[tw] OR } \\
\text { occupational diseases[mh] OR } \\
\text { occupational disease*[tw] OR safety[tw] } \\
\text { OR occupational stress[tw] OR work } \\
\text { stress[tw] OR industrial hygiene[tw] OR } \\
\text { risk management[mh:noexp] OR risk } \\
\text { management[tw] OR risk } \\
\text { assessment[mh] OR risk assess*[tw] OR } \\
\text { safety management[mh] }\end{array}$ & $\begin{array}{l}\text { Students, nursing }[\mathrm{mh}] \text { OR nursing } \\
\text { student*[tw] OR nurse } \\
\text { student*[tw] OR student nurs*[tw }]\end{array}$ \\
\hline
\end{tabular}

\section{Qualitative Research Design}

In 2014 all students within the Bachelor of Nursing at an Australian university were invited to participate in a qualitative study by email. Focus groups were conducted to explore both clinical and non-clinical topics. This paper reports the non-clinical issues only. 
The study was descriptive exploratory in nature (Parse 1996). Two focus groups were conducted in 2014. One group comprised six first year students, the other three third year students. Rubin and Rubin (1995) explained the importance of getting different points of view on a topic and the mix of students in the focus groups conducted enabled this. Some of the students who participated in this study entered university straight from school, others were mature aged students who had held previous jobs. Students of both genders participated. Some came from the country to university, others were from the metropolitan area.

The investigators used a semi-structured questionnaire to facilitate discussion about OHS. With student permission, the sessions (each of approximately one hour duration) were audio-taped and subsequently transcribed. Data were thematically analysed by the investigators following grouping of commonly occurring findings (Braun and Clarke 2006). Prior to commencing the study permission was obtained from the University Ethics Committee.

\section{Results}

This section of the paper presents the results from both the literature review and focus group discussions.

\section{Literature Review}

The results from the comprehensive review of the literature identified the main non-clinical occupational hazards encountered by nursing students were stressors. These included stressors associated with: interpersonal behaviour, work-life balance, and academic work. A secondary topic concerned safe commuting. These research findings come from nursing students globally, including reports from both developed and developing economies.

\section{Interpersonal behavior}

Stressors related to interpersonal behaviours comprised a group of activities including incivility, bullying, and violence. In the United States of America (USA), Clark et al. (2012) investigated faculty and student perceptions of on-line incivility. They recommended the co-creation of acceptable norms and fostering a respectful teaching-learning environment. In a phenomenological study, also in the USA, Mott (2014) reported stressors such as incivility and bullying in the academic setting experienced by nursing students and gave examples of these.

The incidence of peer bullying in nursing students at an English university on two different campuses was investigated by Cooper and Curzio (2012). The authors reported bullying was more prevalent at one campus and was experienced more frequently by first year students than by students further into 
their studies. Verbal and non-verbal modes of bullying occurred more frequently than physical bullying.

South African nursing students' perceptions and experiences of violence associated with their training was studied by de Villiers et al. (2014). The investigators' focus was on the educational setting, being the campus which included a residential facility. The violence students experienced was both physical and psychological in nature. It was perpetrated by fellow students and members of the general public, and attributed primarily to substance abuse. The authors reflected that life on campus mirrored societal violence. Students reported increased anxiety from their experiences and observations of violence.

\section{Work-life balance}

The challenge of managing work-life balance is a stressor for nursing students as Pulido-Martos et al. (2012) reported in their systematic review on sources of stress. Financial concerns may be a stressor (Timmins and Kaliszer 2002). In Australia, where students commonly take on part-time work to help fund themselves while studying, Rella et al. (2008) conducted a longitudinal study on fatigue. They reported students became increasingly fatigued over the years of their undergraduate training and nearing their final year have dangerously high fatigue levels. This comes from continually managing both their paid work and the increasing demands of university study and clinical placements. Female students in India reported financial concerns about inadequate funds to cover their cost of living (Garner et al. 2014). They also reported their struggles of combining work as a nursing student with the requirements of domestic duties. Chow and Kalischuk (2008) investigated selfcare in their study of Canadian nursing students. They found nearly $40 \%$ of students reported not having enough sleep. The investigators also found that although most students said they exercised, 65\% reported they did not spend enough time on exercise. The authors commented that in order to care for self, students need to set time aside regularly and that this can be challenging due to academic and family commitments, and work demands.

\section{Academic work}

As one might expect, academic work was reported as a stressor for students in the systematic review by Pulido-Martos et al. (2012) and in an earlier study by Timmins and Kaliszer (2002) from Ireland. The Indian students in Garner et al.'s study (2014) reported that in relation to their skills, the theory and practice components of their studies ran parallel but did not coincide or correlate with each other, another potential stressor.

\section{Commuting safely}

Students from India reported their concerns for personal safety getting to and from placements at night due to poor public transport and poor security (Garner et al. 2014). Staff from an American University reported being concerned about students commuting in extreme environmental conditions and 
successfully taught classes remotely to keep the students safe and off the roads. Their reflection on this approach was that it worked well (Tucker et al. 2013).

\section{$\underline{\text { Summary }}$}

In summary, the literature provides evidence that there are a number of important non-clinical issues about which students have concerns that are relevant to their health safety and wellbeing. The current study aimed to explore this topic with our own students.

\section{Focus Group Findings}

The principal theme from the focus groups for non-clinical OHS issues was "Pedestrian Concerns". ("Pedestrian" is a term with several meanings. It refers to both activities that are conducted on foot, such as ambulation, and those of an everyday nature). Spanning life both on and off campus, this theme encompassed numerous issues which varied according to location and activity.

Safety on campus and when commuting

Students recognised that the university campus itself may be unsafe. As two first year students reported:

S1: Universities have a bad reputation for being targeted by people. who target other people to mug them or assault them or other things

S2: ... it's a well known thing [safety problem].

Both cohorts of students were aware of the University security service campus safety initiatives to protect students.

First year students reported being apprehensive about where exactly they would go for their clinical experiences, not knowing where placements were located or how to get there by public transport. One student was concerned that some hospitals might be in "dodgy" (unsafe) areas within the community. Another student was concerned about the challenge of commuting to rural areas.

The third years spoke about the expense of communing by taxis if needed for safe travel. One found that getting a male friend to walk her to the bus stop was helpful.

\section{Stress of work-life balance and associated fatigue} fatigue:

The third year students spoke of competing demands and subsequent

S1: Some people come into placement really tired ... run off their feet, with a lot more things on their plate than I have ... .

S2: I guess my biggest issue is fatigue as well, but that's been based around family. Having two young children makes it really quite stressful ... So I don't stop when I go home... So it does make it quite tricky. And 
I'm also by myself so it's even harder... Tackling everything by yourself and then adding the whole study, clinical component on top... You do get tired and I know that when you're tired you can make more mistakes and I do worry about that ... .

Health and wellbeing

When asked about keeping healthy and well for their work as nursing students, one first year student saw this as a responsibility:

S: ...you should have a healthy lifestyle...you should set a good example for the patients, protect yourself so you can protect others.

The students reported a variety of means of keeping healthy and well including: diet (eg cutting down on alcohol), exercise (e.g. sport or walking) and relaxation (e.g. yoga and hobbies), hygiene and appropriate immunisation.

\section{Computer use}

Students commented that having recently attended high school they were accustomed to prolonged periods of computer use. Some students from each cohort described various problems associated with using computers. One, a mature aged third year student, related:

S... coming into uni and having to use computers, a lot of reading and just generally a lot of studying I found it really hard. I was getting a lot of headaches to start with.

Two first year students voiced concerns about equipment hygiene in the campus computer pools:

S1: ...there are many computers, the keyboards get very dirty.

S2:...there are visible crumbs and stains, I feel dirty if I use the keyboards,

I have to wash my hands with antiseptic.

\section{$\underline{\text { Textbooks }}$}

Students reported that the recommended textbooks were heavy. The third years explained:

S1: Textbooks are really big; they're really thick ... .

S2: ... I remember, at the start of First Year, I went and got some text books and then I decided to walk down to the shop to order my uniforms and it was about 40 degrees (Celsius) that day and I didn't realise how far it was in the heat with all my textbooks. I didn't do that the next year.

S3: ... if you're using public transport you're basically lugging that bag around all the time and it does get very heavy and can put a lot of strain on your back. 
The third years also had some suggestions about this:

S1: I was also going to mention online books. That could be a possible remedy but I kind of hate reading on the computer, I prefer to print things off.

S2: a lot of the time [with] the e-books, if you're going to have them to take to and from uni, you sort of need like an iPad or a tablet or like one of those smaller laptops otherwise... .

S3: Bigger laptops are quite heavy.

S1: But I mean not everybody, as a student, especially people coming from high school [they] don't necessarily have the money to afford a tablet or an iPad.

The first years conveyed their thoughts about text books:

S1: Who needs weights when you have Uni Books?

S2: ... at one point I had to get my Mum to pick me up because it was just too much.

Several third years spoke of the discomfort from carrying a backpack of books and the potential of this leading to musculo-skeletal disorders.

\section{Storage}

Some first year students demonstrated a lack of knowledge about (storage) locker availability, their locations and also that you could hire a locker for the year:

\section{S: I didn't realise you could get one.}

The discussion moved on to the cost of hiring one, and students reported they were expensive whereas at high school they had been free of charge.

\section{Transition to university and academic stress}

The third years had some suggestions about how to deal with stress associated with being a first year student. They felt that a mentoring system could be helpful where third years could buddy-up with a first year student, this would then be a way of conveying information about how to get around the university, transport and how to manage academic issues. They felt this would assist the first years to deal with stress:

S: Last year I talked a lot to a third year who I knew from Mt Gambier (rural region) and that really helped me. I was feeling, when is this year going to end and feeling a bit stressed and you know just having someone say it is going to get better that really helped. So I think a buddy program, especially in first year when it's all new and stressful and different [would be helpful]. 


\section{Discussion}

This paper reports on one aspect of a broader pilot study that explored nursing students' impressions and experiences of OHS. Specifically, this paper describes those of a non-clinical nature. The literature reviewed demonstrated that internationally, students have OHS concerns about non-clinical aspects of their undergraduate experiences. These concerns varied between countries in relation to some matters.

The findings of the current study demonstrated that the Australian students experienced some of the issues that have been reported in the international literature namely issues related to campus safety and commuting safely, and the challenges of maintaining a work life balance and the consequent fatigue. These points of similarity will be presented first, and subsequently points of difference will be raised.

Campus security is taken seriously in Australia. University security staff are available to walk students or drive them from campus to their nearby vehicles or public transport after hours. The students all knew about this service from various sources such as emails and their lectures. The students seemed to find they had enough colleagues to walk safely to destinations or walk them to the bus stop or parents who were willing to pick them up from public transport after hours. Nurse safety is a matter which has sparked community concern following several incidents over recent years at a metropolitan hospital close to the university campus. This contrasts with but also aligns with the South African study (de Villiers et al. 2014) where the apparent lack of safety in the residential facility and on campus mirrored conditions in the local community. Similarly students from India (Garner et al. 2014) voiced concerns about lack of security in the community when commuting to and from placement after hours.

Interestingly, the Australian students in the focus groups did not really speak about interpersonal behaviours, such as incivility or bullying as being stressors as has been widely reported in the recent literature. However, this finding is similar to the finding in the Irish study by Timmins and Kaliszer (2002) where interpersonal behaviours were not raised as a prime concern. There may be several reasons for this. First, it may have been either because the students did not feel it was important or perhaps they hadn't experienced it to date, although if there was bullying occurring the third years should have had adequate time to experience this. Alternatively, the students may not have felt comfortable discussing this issue within the focus group setting. Australia does have a number of legislative and policy arrangements that highlight bullying as a behaviour that is not acceptable within the work or study environment.

Juggling work-life balance is a challenge for workers generally (Skinner and Pocock 2014). Nursing students are no exception. Many Australian nursing students work outside their university studies (Rella et al. 2008) to earn an income and/or to gain additional clinical experience. Such activity places demands on their time and competes with time allocated for university studies. 
Some students are able to manage this well by reducing work at key times within their curriculum. Other studies have shown that there is a stress load borne by student nurses and this was supported by students in the present study.

Fatigue is a well known occupational hazard for shift workers including nurses (Rogers 2008). The students were aware of the importance of clinical mistakes they could make as a result of being fatigued (e.g. medication errors) and were keen to manage this proactively, for example by taking on less paid work so as not to be overloaded.

There are findings within the current study which have not been widely reported in the nursing literature that we reviewed. For example, the students reported some concerns related to computer use. In Australia being an adept computer user seems to be the norm for university students (and nursing students), unlike the findings in a Nigerian study where a number of health students (including nursing students) were not at all familiar with computer use (Ajuwon 2003). It is common educational practice in the Australian nursing curriculum to have a number of courses that are undertaken online with minimal direct access to lectures. Therefore use and access to computers is required by all students.

Student concerns about computing in the current study related to time spent on the computer and also computer keyboard cleanliness. One of the mature entry students reported headaches from computer use and reading when they first commenced the course, whereas other students who came straight from high school felt they became accustomed to studying and computer use in their last years of school so this was not an issue for them. A high level of computer use related to musculo-skeletal symptoms has been reported in other student populations (Jenkins et al. 2007). Inappropriate computer set up and use can cause discomfort. This is a matter that can easily be addressed to assist students. In fact, awareness is raised in the presentation to first year students in their introductory lecture on self-care by the Health and Safety Officer. The university has resources on its intranet for students to access about office ergonomics and a self help checklist about equipment set up, however most of these resources relate to desk top computers rather than the portable devices used by many students.

Computer keyboard cleanliness is not an issue that has been reported in relation to nursing students in the literature we reviewed but has been reported in university settings both in Australia (Anderson and Palombo 2009) and the United States (Brooke et al. 2009). Using contaminated keyboards is likely to be related to disease transmission both on campus and within health care settings. This was an unexpected finding. Interestingly, this has been challenging to address on campus, with those managing the computer pools merely suggesting that students use the nearby washroom facilities to cleanse their hands after computer use.

The students raised the issue of carrying heavy textbooks and their storage on campus. Given that Australian nurses have a "no lift" policy it seems that the heaving around of heavy backpacks might not have been given adequate 
consideration. Additionally one of the students spoke of the physical stress of carrying a backpack full of books in very hot weather, both at, and to and from university. These stressors were not reported in the literature we reviewed. This information has since been passed back to the School of Nursing OHS committee for their consideration.

Moving to city from the country or to a new country to study is another challenge students may face. Some of the students found the transition to university a challenge. The third year students' idea of having a buddy or mentor to assist them is a constructive suggestion and hopefully will be taken up by the School of Nursing in the future.

Health and wellbeing are important for nursing students. The current study revealed that students actively engage in self-care which has similarly been reported in a Canadian study by Chow and Kalischuk (2008).

In summary, there were both similarities and differences between the findings from the focus group and the literature reviewed. The similarities related to academic workload, safety on campus and while commuting, and self-care activities. There were international differences between countries such as Australia and South Africa in respect to the widespread violence in the residential setting on campus. There were also differences between Australia and India where the students reported organizational issues of being lowly paid, poorly respected, and overworked and unappreciated by their patients. These are two marked differences. The third key difference related to incivility and bullying which was not an issue the students raised in the focus group.

\section{Limitations}

The methodological approach used in this pilot study presents certain limitations. The number of participants was small. The use of focus groups enabled in-depth discussions, which provided insight into nursing students' experiences and thoughts about OHS. The study was undertaken within one University in Australia therefore the results cannot be generalised. However, the findings may be relevant to educators in other settings and worthy of consideration to enhance the student experience and promote wellbeing.

\section{Conclusions}

Consultation is an important part of the current Australian OHS legislation. Students were able to identify non-clinical hazards when sharing their impressions and experiences within the focus group. Once OHS hazards and concerns are identified, steps can be taken to address them, and the students also provided some suggestions for controls. The findings of this study provide information for consideration by those responsible for not only student nurses wellbeing, health and safety during their university studies, but also for students in other similar professional undergraduate courses. This information 
has been conveyed to relevant staff with the aim of making the university learning experience for nursing students a positive one.

\section{References}

Ajuwon GA (2003) Computer and internet use by first year clinical and nursing students in a Nigerian teaching hospital. BMC Medical Informatics and Decision Making 3(10).

Australian Safety and Compensation Council (2008) Occupational Exposures of Australian Nurses. Retrieved from http://bit.ly/1IoJj75

Anderson G, Palombo EA (2009) Microbial contamination of computer keyboards in a university setting. American Journal of Infection Control 37(6): 507-509.

Braun V, Clarke V (2006) Using thematic analysis in psychology. Qualitative Research in Psychology 3(2): 77-101.

Brooke JS, Annand JW, Hammer A, Dembkowski K, Shulman ST (2009) Investigation of bacterial pathogens on 70 frequently used environmental surfaces in a large urban U.S. university. Journal of Environmental Health 71(6): 17-22.

Chow J, Kalischuk R (2008) Self-care for caring practice: student nurses perspectives. International Journal of Human Caring 12(3): 31-37.

Clark CM, Werth L, Ahten S (2012) Cyber-bullying and incivility in the online learning environment, Part 1: Addressing faculty and student perceptions. Nurse Educator 37(4): 150-156.

Cooper B, Curzio J (2012) Peer bullying in a pre-registration student nursing population. Nurse Education Today 32(8): 939-44.

de Villiers T, Mayers PM, Khalil D (2014) Pre-registration nursing students' perceptions and experiences of violence in a nursing education institution in South Africa. Nurse Education in Practice 14: 666-673.

Garner SL, Raj L, Prater LS, Putturaj M (2014) Student nurses' perceived challenges of nursing in India. International Nursing Review 61(3): 389-397.

Jenkins M, Menendez CC, Amick BC, Tullar J, Hupert N, Robertson MM, Katz JN (2007) Undergraduate college students' upper extremity symptoms and functional limitations related to computer use: A replication study. Work 28(3): 231-238.

Mott J (2014) Undergraduate nursing student experiences with faculty bullies. Nurse Educator 39(3): 143-148.

National Institute of Occupational Safety and Health (2014) Workplace Safety and Health Topics, Industries \& Occupations, Healthcare. Retrieved from http://www.cdc.gov/niosh/topics/healthcare/. [Accessed: 16 September 2014]

Parse RR (1996) Building knowledge through qualitative research: The road less traveled. Nursing Science Quarterly 9(1): 10-15.

Pulido-Martos M, Augusto-Landa JM, Lopez-Zafra E (2012) Sources of stress in nursing students: A systematic review of quantitative studies. International Nursing Review 59: 15-25.

Rella S, Winwood PC, Lushington K (2008) When does nursing burnout begin? An investigation of the fatigue experience of Australian nursing students. Journal of Nursing Management 17: 886-897.

Rogers AE (2008) The effects of fatigue and sleepiness on nurse performance and patient safety. In. RG Hughes (edn.). Patient Safety and Quality: An Evidence- 
Based Handbook for Nurses. Rockville: Agency for Healthcare Research and Quality, p. 509-545.

Rubin RJ, Rubin IS (1995) Qualitative Interviewing: The Art of Hearing Data. Thousand Oaks: Sage Publications.

Skinner N, Pocock B (2014). Australian Work and Life Index, 2014. The Persistent Challenge: Living, Working and Caring in Australia in 2014. Centre for Work and Life, University of South Australia.

Stokowski LA (2014) The Risky Business of Nursing. Retrieved from http://wb.md/1T6mA5I. [Accessed: 22 January 2014]

Timmins F, Kaliszer M (2002) Aspects of nurse education programmes that frequently cause stress to nursing students - fact-finding sample survey. Nurse Education Today 22: 203-211.

Tucker CA, Bradshaw MJ, Ketcham N (2013) Teaching and learning in a winter wonderland. Nurse Educator 38(4): 164-168. 